Contents List available at VOLKSON PRESS
Education, Culture and Social Development (ECSD)
DOI : http://doi.org/10.26480/icecsd.01.2018.46.50
Journal Homepage: : https://topicsonsocialdevelop.com/

\title{
INFLUENCE OF CULTURAL BACKGROUND KNOWLEDGE ON ENGLISH READING
}

\author{
Yang Lu \\ Wuhan University of Technology, School of Foreign Language, Wuhan, China \\ *Corresponding Author Email: 1477158272@qq.com
}

This is an open access article distributed under the Creative Commons Attribution License, which permits unrestricted use, distribution, and reproduction in any medium, provided the original work is properly cited

\section{ARTICLE DETAILS}

\section{Article History:}

Received 12 November 2017

Accepted 12 December 2017

Available online 1 January 2018

\section{ABSTRACT}

Language and culture are associated with each other and culture occupies an obvious status in English reading. However, the traditional teaching method lays emphasis on vocabulary, sentence and grammar. And it ignores the great influence of cultural background knowledge. Though investigation the author finds that a lot of students do not have strong awareness to apply culture background knowledge in English reading. Some students who have realize the importance of culture background knowledge have no idea about how to apply it in English reading. This paper first emphasis the importance of cultural background knowledge in English reading and then proposes several ways of building cultural background knowledge. In this paper, questionnaire, reading comprehension test and teaching experiment are used to confirm the author's research hypothesis.

\section{KEYWORDS}

English reading comprehension, culture background knowledge.

\section{INTRODUCTION}

With the development of global economy and society, the trend of economic and cultural integration appeared. And the international cooperation and communication is increasing. English is occupying a more and more important status [1]. So, more and more people begin to learn English. English even becomes the most important foreign language to Chinese students. And reading is of great importance, which is the basic way of obtaining a foreign language and the most important skill among the four basic language skills [2]. To master a foreign language well, we have to get enough input by reading.

However, many students' reading ability is still poor even if they do much reading every day. That is exactly because they ignore the importance of cultural background knowledge [3]. Many students just master a large quantity of knowledge about vocabulary, phonetics and grammar. They pay no attention to culture, which is closely associated with language. It is obviously not the right way of reading. American linguist Edward Sapir says: "Language cannot exist without culture. Culture can be explained as what the society thinks and does, and language is the expression of the ideas of the society" [4]. From what he says we can see that culture reflects language and occupies a vital position in mastering a foreign language.

The purpose of this paper is to help students and teachers realize the important role that cultural background knowledge plays in reading comprehension and to improve students' reading ability efficiently [5]. readers are not able to understand the deep meaning of a passage without adequate background knowledge and it is the lack of background knowledge that causes students' poor reading comprehension. This paper will present the influence of cultural background knowledge and illustrate the necessity of mastering enough culture knowledge in English reading.

\section{CULTURAL BACKGROUND KNOWLEDGE IN ENGLISH READING}

\subsection{The introduction of reading}

\subsubsection{The Concept of Reading}

Reading is the main way for people to get language input and one of the four basic English skills. For many years, notions of reading have changed a lot. In the first definition, reading was defined as a decoding process and learning to read means learning to identify words. Reading used to be regarded as a one -way flow of information to the brain [6]. It is now thought to be a two-way communication between readers' brain and the passage. The second definition defines reading as combing meaning with a text and a creative activity between the reader and the text.

Although there have been various definitions of reading, it is hard to define it just in a single sentence. According to Smith: "instead of mechanically pronouncing sound from the passage, reading is a constructive process of making sense of the text". Many researchers agree that the central purpose of reading is to produce meaning [7]. At present, a more inclusive definition of reading is supported by many researchers. We tend to support Dechant's definition which defines reading as "building a representation of text by relating what is on the page to one's own fund of experience. Reading involves text, reader, and the interaction between text and reader [8]. Anthony holds that reading is a process producing meaning by making use of the readers' previous knowledge, the information expressed by the passage, and the context. We can notice that the style of the text, figure of speech, grammar and vocabulary all have great impact on reading comprehension. However, reading may differ when readers come from different culture, family and education. American psychologist Goodman points out that reading is: "a psycholinguistic guessing game in which the reader reconstructs meaning encoded by a writer as a graphic display".

In a word, reading is a complex process of interaction among the reader, writer and the text, which involves the readers pre-exist background knowledge, the present context, and the specific text being read.

\subsubsection{Reading Comprehension}

Reading comprehension is the ability of reading passage, processing it and making sense of its meaning. It is not easy to teach, learn or practice reading comprehension though its definition may seem simple. Before the 1970s, reading comprehension means decoding language before the 
1970s [9]. Reading comprehension is defined as the level of understanding of a text. This understanding comes from the interaction between the words and how they trigger knowledge outside the text. An individual's ability to understand a text is influenced by a lot of factors, such as their characteristics and skills, one of which is the ability to make inferences. When there are difficult words in a passage, students always use too much of their processing capacity to understand individual words, which has great impact on their ability of making sense of what they are reading. Comprehension is a "creative, multifaceted process" dependent upon four language skills: phonology, syntax, semantics, and pragmatics. As the cognitive process develops, great importance has been attached to the function of nonlinguistic knowledge in reading comprehension. Fergus I.M.

Craik and Robert S. Lockhart first put forward a theory: Reading comprehension involves various processes, including shadow processing and deep processing. Shadow processing involves structural and phonemic recognition, the processing of sentence and word structure and their associated sounds [10]. Deep processing involves semantic processing, which happens when we encode the meaning of a word and relate it to similar words. There are some specific factors that determine how successfully an individual will comprehend a text. According to schema theory, reading comprehension is the result of the interaction between the background knowledge of the reader and the reading materials. Schema theory plays a vital role in reading comprehension. Such as, assisting students in absorbing information, attracting student's attention for important information, helping readers search memories methodically. So, teachers should realize the importance of developing students' schema in teaching reading. Students should attach great importance to schemata while they are reading.

\subsection{The Introduction to Culture}

\subsubsection{The Definition of Culture}

There are distinct kinds of definitions of culture. Background knowledge encompasses cultural knowledge, social knowledge, common senses, linguistic knowledge, etc. From common knowledge to very specialized knowledge, it includes the knowledge of the world. In terms of language teaching perspective, it refers to individuals previous world knowledge and special knowledge on a certain subject.

As for culture, there are all kinds of definitions from different experts. Sir Edward B. Tylor first gave a profound scientific concept of culture in 1871. He believed that culture, or civilization, taken in its broad, ethnographic sense, is that complex whole which includes knowledge, belief, art, morals, law, custom, and any other capabilities and habits acquired by man as a member of society. Culture is the characteristics and knowledge of a particular group of people, defined by everything from language, religion, cuisine, social habits, music and arts. Culture refers to the pattern of human activity and the symbols which give significance to this activity. Culture is represented through the art, literature, costumes, customs, and traditions of a community. Different cultures exist in different parts of the word.

\subsubsection{The Importance of Culture}

From the above discussions, we realize that culture plays a very important role in reading comprehension. And culture itself is of great importance. Culture is a bond that ties the people of a region or community together. It is the one common bond that brings the people of a community together. The customs and traditions that the people of a community follow, the festivals they celebrate, the kind of clothing they wear, the food they eat, and most importantly, the cultural values they adhere to, bind them together. The cultural values help develop a sense of belonging, and a feeling of unity in the minds of the people of that particular culture. Culture is seen as a system of social control, wherein people share their standards and behavior. The cultural values from the founding principles of one's life. They influence one's principles and philosophy of living. They impact our way of living and thus affect our social life. In a word, the importance of culture lies in the fact that it is a link between people and their value systems.

\subsubsection{The Application of Culture in English Reading}

It is no doubt that cultural background knowledge occupies a significant position in English reading. We often find that readers cannot understand the passage they are reading even though they are aware of the meaning of the words and grammar structures in it. The reason of this phenomenon is that the readers don't master enough cultural background knowledge. They don't realize that there are cultural differences in the language they are learning. Without adequate cultural background knowledge relating to a text, it is impossible to understand the language in reading.

Phillips once pointed out: "a successful reading of any passage depends upon a combination of linguistic knowledge, cognitive skill and general experience and knowledge of the world, whether acquired by experience or by learning, influence greatly the reading comprehension process, for the more the reader brings to the text, the more is taken away". We cannot get the deep meaning behind lines without the help of cultural background knowledge, because a word may have different meanings in different circumstances of culture. Thus, if Chinese students do not know anything about western culture, including customs, histories, life style and values, he or she may not able to comprehend the exact meaning of the passages.

\section{RESEARCH METHODOLOGY}

\subsection{Introduction}

The previous chapter has discussed the theoretical framework, including schema theory, reading theory. In this chapter an experimental method will be used to find out cultural influence on English reading. This chapter are made up of the introduction to research questions, subjects, instruments, and procedures. The data of this experiment will be discussed in detail.

\subsection{Research Questions}

Although a lot of reading research studies have been conducted to prove the importance of cultural background knowledge, there are still some problems that need to be solved. This study is aimed at finding out the cultural awareness of students. and helping students to improve their reading comprehension. Besides, by analyzing the cultural influence on English reading, the author tries to put forward some effective measures and practical guidance for students to improve their reading ability. Here are the research questions of this study:

1. What are the main problems in English reading comprehension? 2.What are the opinions students hold towards cultural background knowledge?

3.How much cultural background knowledge have students grasped? 4.Can the mastery of cultural background knowledge improve students reading comprehension?

5.What are the effective measures based on schema theory to improve students reading comprehension?

\subsection{Subjects}

The subjects of this study consist of 100 freshmen. They are English majors from Hubei University of Arts and Science. The author chose them as the subjects for the following reasons: (1) They are freshmen, they are more enthusiastic about learning; (2) The just graduated from high school, they don not leave behind English reading for a long time; (3) They are English majors, so they have done more English reading than students in other majors and are more eager to improve their reading. The 100 students will be divided into two groups. The first one will be taught schema theory in reading, while the other group will be taught in traditional way. All the participants will be asked to take pre-test, post-test and answer the questionnaire.

\subsection{Instruments}

The instruments used in this study involves reading comprehension tests and a questionnaire. 


\subsubsection{Test}

The tests include pre-test and post-test. They are used to find out how cultural background knowledge affect the reading ability of English majors. First of all, the author will hand out the pre-test to two groups. This part can ensure the effectiveness of the study. Through the pre-test we can see whether the two groups are at the same or similar level. Only if the two groups are at the same level on reading can we guarantee the validity of the research. The participants will be given 30 minutes to finish the reading. Secondly, after 10 weeks' training, the author will two groups a post-test, which is to find out whether there is difference between the two groups and whether the cultural background knowledge can help students improve their reading skills.

\subsubsection{Questionnaire}

The questionnaire is aimed to investigate the students' reading problems, cultural background knowledge, reading habits and reading strategies. Though the questionnaire the author wants to find the difficulties of students in reading and how much cultural background knowledge students have mastered.

\subsection{Procedures}

The experiment lasted for about 11 weeks, from September to November in 2016. The author will use one lesson a week to teach schema theory for the experiment group. The procedures of the experiment are questionnaire, pre-test, and post-test.

In the first stage, the questionnaires were handed out to subjects in September 10th, 2016. Before the test, the author uses a questionnaire to see whether students know some cultural background knowledge and what are the biggest difficulties they encounter in reading. All the 100 students in the experimental group and comparison group are asked to finish the questionnaire. There are 100 questionnaires were sent out by the author. By analyzing the questionnaires, we can know that students don not know much about cultural background knowledge and they also don not have the awareness of applying it in English reading.

In the second stage, the author organized the pre-test in September 14th, 2016. All the 100 students in the two groups are required to take the test. The students both in experimental group and comparison group are demanded to finish the same test paper within the same time. After finishing the test, the author collected the data of the pre-test and found that students both in experimental group and comparison group are at the same level in reading.

In the third stage, the author began 10weeks' teaching experiment. Two different teaching methods are adopted in two groups. The reading comprehension teaching method based on schema theory was applied in the experimental group. Teachers introduced schema theory and taught much cultural background knowledge to students. With the help of teachers, the students in experimental group learned how to apply cultural background knowledge in English reading. While in the comparison group, traditional teaching method was adopted in teaching class. In class, the teacher read the text word by word, explained new words and translated the passage sentence by sentence. The teacher did not teach any cultural background knowledge.

In the fourth stage, the author conducted the post-test. Both groups are asked to take the examination. After the post-test, the author collected the data of it and compared it with the data of the pre-test.

\section{RESULTS AND DISCUSSIONS}

The research questions will be discussed in this chapter. It firstly showed a detailed description of the data which is collected from the questionnaire, pre-test and post-test. And then the data will be analyzed.

\subsection{Data Analysis of the Questionnaire}

Table 1: Question about the the quantity of reading.

\begin{tabular}{|l|l|l|l|l|}
\hline & \multicolumn{2}{|c|}{ Experimental group } & \multicolumn{2}{l|}{$\begin{array}{l}\text { Comparison } \\
\text { group }\end{array}$} \\
\hline $\begin{array}{l}\text { Question } \\
\text { number }\end{array}$ & $\mathrm{A}$ & $\mathrm{B}$ & $\mathrm{A}$ & $\mathrm{B}$ \\
\hline 1 & $10 \%$ & $90 \%$ & $15 \%$ & $85 \%$ \\
\hline
\end{tabular}

The question: do you think you have a large quantity of reading? No matter experimental group or comparison group, most students choose the answer A. That means that most students don not do much reading and only a few students do much reading training. So, we can see that the general situation of students' reading quantity is not positive, they do not have the awareness of doing reading training. In order to improve reading ability, a lot of training is of great necessity. So, it is important for students to improve their reading quantity.

Table 2: As for the question: do you think new words and complex sentences are the biggest difficulties in reading?

\begin{tabular}{|l|l|l|l|l|}
\hline & \multicolumn{2}{|c|}{ Experimental group } & \multicolumn{2}{l|}{$\begin{array}{l}\text { Comparison } \\
\text { group }\end{array}$} \\
\hline $\begin{array}{l}\text { Question } \\
\text { number }\end{array}$ & $\mathrm{A}$ & $\mathrm{B}$ & $\mathrm{A}$ & $\mathrm{B}$ \\
\hline 2 & $75 \%$ & $25 \%$ & $70 \%$ & $30 \%$ \\
\hline
\end{tabular}

From the table we can see that about $75 \%$ of the experimental group think that new words and complex sentences are the main difficulties they encounter in reading; about $70 \%$ of the students from the experimental group hold the same view. According to the data, we can draw a conclusion that students of both two groups ignore the cultural background knowledge and think new words and complex sentences are the most difficult problems in reading.

Table 3: A survey about schema theory, as for the question: do you know schema theory?

\begin{tabular}{|l|l|l|l|l|}
\hline & \multicolumn{2}{|l|}{$\begin{array}{l}\text { Experimental } \\
\text { group }\end{array}$} & \multicolumn{2}{l|}{$\begin{array}{l}\text { Comparison } \\
\text { group }\end{array}$} \\
\hline $\begin{array}{l}\text { Question } \\
\text { number }\end{array}$ & $\mathrm{A}$ & $\mathrm{B}$ & $\mathrm{A}$ & $\mathrm{B}$ \\
\hline 3 & $5 \%$ & $95 \%$ & $3 \%$ & $97 \%$ \\
\hline
\end{tabular}

From the table we can see that nearly all students of both two groups don not know schema theory. Only a few students have heard about schema theory, but they don't have deep understand about the theory. The main reason of this situation is that teachers teach students with the traditional method. Under the influence of traditional method, students don't have the opportunity to learn about schema theory. So, teachers should play the role of introducing schema theory to students.

Table 4: A survey about the role of cultural background knowledge; as for the question, as for the question: do you think cultural background knowledge is of use for reading?

\begin{tabular}{|l|c|c|c|c|}
\hline & \multicolumn{2}{|c|}{ Experimental group } & \multicolumn{2}{c|}{ Comparison group } \\
\hline $\begin{array}{l}\text { Question } \\
\text { number }\end{array}$ & $\mathrm{A}$ & $\mathrm{B}$ & $\mathrm{A}$ & $\mathrm{B}$ \\
\hline 4 & $13 \%$ & $78 \%$ & $16 \%$ & $84 \%$ \\
\hline
\end{tabular}

The table shows that only $13 \%$ of the students in experimental group and $16 \%$ of students in comparison group realized the importance of cultural background knowledge; $78 \%$ of the students in experimental group and $84 \%$ of the students in comparison don't think cultural background knowledge is important. Being habituated to using traditional method, students don't pay much attention to cultural background knowledge. So, it is urgent for teachers to seek a new teaching method. 
Table 5: Question have you stored a lot of cultural background knowledge?

\begin{tabular}{|l|c|c|c|c|}
\hline & \multicolumn{2}{|c|}{ Experimental group } & \multicolumn{2}{c|}{ Comparison group } \\
\hline $\begin{array}{l}\text { Question } \\
\text { number }\end{array}$ & $\mathrm{A}$ & $\mathrm{B}$ & $\mathrm{A}$ & $\mathrm{B}$ \\
\hline 5 & $3 \%$ & $97 \%$ & $5 \%$ & $95 \%$ \\
\hline
\end{tabular}

From the table we can see that students in both two groups don't grasp much cultural background knowledge. In reading process, students pay much attention to new words and complex sentences. So, they spent much time on memorizing vocabulary and learning grammar. It is hard for students to improve their reading ability if they don't have grasp much cultural background knowledge.

Table 6: As for the question: will you apply cultural background knowledge in reading?

\begin{tabular}{|l|l|l|l|l|}
\hline & \multicolumn{2}{|l|}{$\begin{array}{l}\text { Experimental } \\
\text { group }\end{array}$} & \multicolumn{2}{c|}{ Comparison group } \\
\hline $\begin{array}{l}\text { Question } \\
\text { number }\end{array}$ & A & B & A & B \\
\hline 6 & $10 \%$ & $90 \%$ & $12 \%$ & $88 \%$ \\
\hline
\end{tabular}

According to the table, only a few students sometimes will use the cultural background knowledge they have stored while they are reading. Prediction is an effective way of improving the efficiency of reading. Perhaps some students will use cultural background knowledge to guess the contents of reading materials. But most of them cannot make prediction for the text with the help of cultural background knowledge. There are some reasons accounting for this phenomenon: first of all, students don't knowledge about cultural background knowledge; secondly, teachers' pay no attention to cultivate student's awareness of using cultural background knowledge.

\subsection{Data Analysis of the Test}

This part will analyze the result of the pre-test and post-test of the participants. There is some explanation about the test. The test papers are complete papers, so the scores of pre-test and post-test are hundred mark system. Both pre-test and post-test include 30 single choice questions for a total of 60 scores and 20 multiple choice questions for a total 40 scores. The score given in the chart is the average score of each group.

Table 7: Difference between the average score of students in experimental group and comparison group

\begin{tabular}{|l|c|l|l|l|}
\hline \multirow{2}{*}{} & \multicolumn{2}{|c|}{ Experimental group } & \multicolumn{2}{c|}{$\begin{array}{l}\text { Comparison } \\
\text { group }\end{array}$} \\
\cline { 2 - 5 } & Pre-test & Post-test & Pre-test & $\begin{array}{l}\text { Post } \\
\text {-test }\end{array}$ \\
\hline $\begin{array}{l}\text { Average } \\
\text { score }\end{array}$ & 56 & 86 & 58 & 60 \\
\hline
\end{tabular}

From the table we can see that there is not much difference between the average score of students in experimental group and comparison group. So, it indicates that students in these two groups are at similar reading level before the teaching experiment. After the teaching experiment, it can be seen that students in experimental group make great progress in the post-test. For the students in comparison group, the improvement is not obvious. After being taught by the teaching method based on cultural schema theory, the reading ability of students in experimental group obviously improved, which fully embodies the good effect of teaching experiment. The new teaching method introduces cultural background knowledge into reading, which plays a significant role in helping students improve reading ability.

\subsection{Methods of Building Cultural Background Knowledge}

From the results of the research we can see that new teaching method based on schema theory is very efficient. Schema theory research shows that if a reader has greater background knowledge of a text, he/she will comprehend that text better. The main reason of students' poor reading ability is that they lack adequate cultural background knowledge.

On the one hand, teachers can help students build cultural background knowledge by appropriate pre-reading activities. There are all kinds of pre-reading activities. Such as watching movies, class discussions, the direct teaching of cultural background knowledge, and so on. On the other hand, students can store cultural background knowledge by extensive reading. Building cultural background knowledge by reading is a effective method which is often ignored. Students can try to read different kinds of books such novels, history book, science books, and so on.

\section{CONCLUSION}

\subsection{Major Findings}

This paper is a tentative investigation into the influence of cultural background knowledge on reading. After comparing the traditional teaching method and new teaching method, the major findings are presented as follows: cultural background knowledge can help students improve their reading ability and the new teaching method involving cultural background knowledge has great effect on reading comprehension teaching.

Reading is an interactive process which involves students' background knowledge. So, it is important for students to build cultural background knowledge and apply it in reading. Teachers should have the awareness of using cultural background knowledge to teach English reading. If readers have enough cultural background knowledge, they will have a better comprehension of text. It will be hard for readers to comprehend the deep meaning of passage without related cultural background knowledge.

\subsection{Limitations of the Study}

This experimental study illustrates that the application of cultural background knowledge to English reading is of great significance for improving reading ability. However, although the author has tried her best to guarantee the reliability and validity of the study, there still exists some limitations in this experimental study. Firstly, the subjects for the study are all English majors. The size of the sample may be limited because they all major in English. Secondly, the experimental period is not long enough. 11 weeks is a short period of time, which is not enough for applying schema theory. Thirdly, the reading comprehension tests are not so scientific, which all consist of choice questions. Students may choose the correct answer by luck.

\section{REFERENCES}

[1] Alderson, J.C., Urquhart, A.H. 1983. Introduction: what is reading [M]. Cambridge: CUP.

[2] Aebersold, J.A., Field, M.L. 1997. From Reader to Reading Teacher [M]. New York: Cambridge Press.

[3] Anderson, E. 1992. Read the changes [M]. Buckingham: Open University Press.

[4] Bartlett, F.C. 1932. Remembering[M]. Cambridge: Cambridge University Press.

[5] Carrel, P.L. 1983. Three components of Background Knowledge in Reading Comprehension [M]. Cambridge: CUP.

[6] Carrel, P.L. 1983. Three components of background knowledge in reading comprehension [J]. Language Learning, (33), 183-207.

[7] Christine, N. 2002. Teaching Reading Skills in a Foreign Language [M]. Shanghai: Shanghai Foreign Language Education Press.

[8] Davis, F. 1995. Introducing Reading[M]. London: Penguin. 
[9] Grellet, F. 2000. Developing Reading Skills [M]. Beijing: People's Education Press.

[10] Silberstein, S. 2002. Techniques and in Teaching Reading [M]. Shanghai: Shanghai Foreign Language Education Press.

\section{APPENDIX}

A questionnaire about Reading The questionnaire aims to find the main problems that readers meet in reading. On the basis of schema schema theory, this questionnaire is designed.Please read the following items carefully and make you own choice.There are just two choices in each item.Your answer is only to offer data to make some research.

1 Do you think you have a large quantity of reading?
A Yes
B No

2 Do you think new words and complex sentences are the biggest difficulties in reading?
A Yes
B No

3 Do you know schema theory?
A Yes
B No

4 Do you think cultural background knowledge is of use for reading?

$$
\text { A Yes B No }
$$

5 Have you stored a lot of cultural background knowledge?
A Yes
B No

6 Will you apply cultural background knowledge in reading?
A Yes
B No 